\title{
Aortic and biventricular function in pediatric meningococcal septic shock survivors as assessed with MRI
}

\author{
Heynric Grotenhuis ${ }^{1 *}$, Hennie Knoester ${ }^{2}$, Jos J Westenberg ${ }^{1}$, Lucia JM Kroft ${ }^{1}$, Albert de Roos ${ }^{1}$ \\ From 15th Annual SCMR Scientific Sessions \\ Orlando, FL, USA. 2-5 February 2012
}

\section{Summary}

Septic shock is one of the major causes of death in children and is characterized by a massive inflammatory response. To present date, no studies have been performed to assess the impact of such an 'inflammatory hit' on aortic wall structure and myocardial performance.

This study shows that despite adequately preserved systolic biventricular function, frequently reduced aortic elasticity may indicate aortic wall pathology, being associated with biventricular hypertrophy and concomitant delayed biventricular relaxation in pediatric patients after septic shock.

\section{Background}

Septic shock is one of the major causes of death in children and is characterized by a massive inflammatory response. To present date, no studies have been performed to assess the impact of such an inflammatory hit' on aortic wall structure and myocardial performance. The objectives of the current study were therefore to prospectively assess aortic elasticity and biventricular systolic and diastolic function in a group of pediatric patients after meningococcal septic shock by using MRI.

\section{Methods}

Eighteen pediatric meningococcal septic shock survivors (8 male; mean age \pm standard deviation 14.5 years \pm 3.9 ; imaging performed 8.2years \pm 2.4 after septic shock) treated with at least 2 inotropic and vasoconstrictive agents for 48 hours or longer and 18 for age and gender

${ }^{1}$ Radiology, Leiden University Medical Center, Leiden, Netherlands Full list of author information is available at the end of the article matched controls were prospectively studied. Routine MRI was used to assess aortic pulse wave velocity (PWV) and systolic and diastolic biventricular function. Independent-samples-t-test and Pearson-correlationcoefficient were used for statistical analysis.

\section{Results}

Sepsis patients showed reduced aortic elasticity vs. controls (PWV in aortic arch: $4.1 \mathrm{~m} / \mathrm{s} \pm 0.3$ vs. $3.3 \mathrm{~m} / \mathrm{s} \pm 0.5$, $\mathrm{P}<0.01$; PWV in descending aorta: $3.9 \mathrm{~m} / \mathrm{s} \pm 0.9$ vs. $3.2 \mathrm{~m} / \mathrm{s}$ $\pm 0.4, \mathrm{P}<0.01)$. Systolic biventricular function was preserved (LV ejection fraction $57 \% \pm 8$ vs. $56 \% \pm 6, \mathrm{P}=0.74$; RV ejection fraction $56 \% \pm 8$ vs. $52 \% \pm 6, \mathrm{P}<0.01$ ), whereas biventricular mass was increased (LV $52.1 \mathrm{gram} / \mathrm{m} 2 \pm 8.4$ vs. $36.0 \mathrm{gram} / \mathrm{m} 2 \pm 9.9, \mathrm{P}<0.01$; RV $26.8 \mathrm{gram} / \mathrm{m} 2 \pm 6.5$ vs. $10.4 \mathrm{gram} / \mathrm{m} 2 \pm 5.0, \mathrm{P}<0.01)$. Also, delayed biventricular relaxation was found after sepsis: peak filling rates corrected for end-diastolic-volume (PFREDV) across the mitral and tricuspid valve were significantly reduced (mitral: PFREDV of E wave $2.54 \pm 0.56$ vs. $3.08 \pm 0.63$, $\mathrm{P}=0.01$; PFREDV of A wave $1.10 \pm 0.26$ vs. $1.31 \pm 0.30$, $\mathrm{P}=0.03$; tricuspid: PFREDV of $\mathrm{E}$ wave $1.81 \pm 0.44$ vs. 2.09 $\pm 0.29, \mathrm{P}=0.04$; PFREDV of A wave $1.11 \pm 0.22$ vs. 1.42 $\pm 0.39, \mathrm{P}<0.01)$. Increased PWV in aortic arch and descending aorta were associated with increased LV mass $(\mathrm{r}=0.62, \mathrm{P}<0.01$, and $\mathrm{r}=0.51, \mathrm{P}<0.01$, respectively) and delayed LV relaxation parameters.

\section{Conclusions}

Despite adequately preserved systolic biventricular function, reduced aortic elasticity in pediatric patients after septic shock may indicate aortic wall pathology, being associated with biventricular hypertrophy and concomitant delayed biventricular relaxation. Long-term prognosis after septic shock may therefore be adversely 
affected considering the cumulative effects of cardiovascular disease during a lifetime.

\section{Funding}

No disclosures.

\section{Author details}

${ }^{1}$ Radiology, Leiden University Medical Center, Leiden, Netherlands. ${ }^{2}$ Pediatric

Intensive Care, Emma Childrens Hospital AMC, Amsterdam, Netherlands.

Published: 1 February 2012

doi:10.1186/1532-429X-14-S1-P199

Cite this article as: Grotenhuis et al:: Aortic and biventricular function in pediatric meningococcal septic shock survivors as assessed with MRI.

Journal of Cardiovascular Magnetic Resonance 2012 14(Suppl 1):P199.

Submit your next manuscript to BioMed Central and take full advantage of:

- Convenient online submission

- Thorough peer review

- No space constraints or color figure charges

- Immediate publication on acceptance

- Inclusion in PubMed, CAS, Scopus and Google Scholar

- Research which is freely available for redistribution

Submit your manuscript at www.biomedcentral.com/submit
C Biomed Central 